\title{
A Data-Driven Condition Monitoring of Product Quality Analysis System Based on RS and AHP
}

\author{
Jihong PANG, Ruiting WANG, Quan XIAO, Feifei QIN
}

\begin{abstract}
Mechanical and electrical products have complex structure and intelligent control system, their reliability plays an important role in the normal operation of security facilities. However, most manufacturers usually pay more attention to the product designing and manufacturing quality, with little interest in the intelligent fault diagnosis. The objective of this study is to develop the products quality intelligent analysis and management system based on Rough Set (RS) and Analytic Hierarchy Process (AHP). Firstly, this paper reviews the principle of hardware, software design, monitoring platform and quality analysis system to reduce the number of information transfer with computer technology. Secondly, the fault types and feature extractions of different faults of elevators are presented and simplified by using RS theory. Then, the objective weight of level index model can be obtained by AHP method, and the comprehensive analysis weight of each index is obtained by using the value of subjective and objective weight coefficients with the golden ratio. Finally, a comprehensive decision weight of the major index for quality control analysis system of many vertical elevators is presented. The results show that the data-driven condition monitoring and quality analysis system is a kind of important means to prevent a disaster of complex mechanical and electrical products.
\end{abstract}

Keywords: analytic hierarchy process; data-driven condition monitoring; fault information; mechanical and electrical products; quality analysis system; rough set

\section{INTRODUCTION}

The ability to predict a failure of quality analysis system for complex mechanical and electrical products before it happens would be tremendously valuable to management and maintenance staff. Due to the high cost of failure, a policy of zero failure must be strictly enforced with quality analysis and critical control point management system implemented. The principle of operation fault should be adopted in product quality, which accounts better for the situation in industry. So, development and application of product quality analysis system are a fundamental guarantee for the failure diagnosis. Based on Markov model of quality analysis system, a Markov model in a two-stage manufacturing system with remote quality information feedback was developed [1]. A Markov model to analyze quality propagation in multi-stage manufacturing systems was also developed [2, 3]. An analytical method to evaluate the quality performance of flexible manufacturing systems was approved [4]. A distributed multi-agent system for air quality monitoring and analysis was presented by using the computer network distribution [5]. In this paper, we describe our design on quality analysis system for complex mechanical and electrical products according to practice request. We then expound on roughly the constitution and the main characters of the products quality system through systematic analysis and integration. Product quality analysis, fault diagnosis, database, network and other technology were banded together to build an extensible fault diagnosis system for mechanical and electrical products. A software service was also used to manage and control product quality in a real-time manufacturing industry [6]. The mechanism responsible for the influence of the laser beam quality factor was evaluated by using the finite element and angular spectrum theory. An integrated strategy considering product quality level and mission reliability state was proposed for the intelligent manufacturing process [7]. The organization shall continually improve the effectiveness with a sound quality decision support system, first-class analysis and testing tools. Thus, these quality enabled factors of product design stage were identified and analyzed to present a hierarchybased model [8]. Moreover, an automatic logging analysis system was proposed to construct a convenient test environment for mobile devices using a record analysis program. The performance measures of process quality, throughput and process capability were used to handle complexity in mixed model assembly systems. It is responsible for establishing and maintaining the quality analysis system that performs on-line monitoring the level of products quality with the aim to improve the current quality of complex mechanical and electrical products.

On the other hand, failure can result in serious accidents of the products control system, so it is significant to monitor the condition of fault information. A data-driven condition monitoring of fault information and quality analysis system can ensure achieving the target of maintenance for complex mechanical and electrical products. A system with real production data was presented to diagnose the manufacturing processes in the electronics industry [9]. The knowledge on utilizing online analytical technology to process complex equipment state is key to data-driven condition fault monitoring and quality analysis technology. Moreover, the industrial process data was used to estimate the parameters in the model and basic functions based on recursive least squares method and data-driven approach. A new quality assurance philosophy for process monitoring for quality was developed by using the big data style of thinking. A combination of cluster analysis and supervised machine learning was presented to product state data along the manufacturing program towards higher product and process quality [10]. Characteristic extraction of movement data is a key step in the condition monitoring and quality analysis of intellectual equipment. Many statistical process monitoring and control methodologies in steel facilities were presented to improve product quality [11]. By taking account of users' feedback to quality decision system, the product fault of analysis system can be used to solve the decision problem. So, staff managing on using and maintaining devices requires appropriate professional training and a condition monitoring of fault 
information and quality analysis data. Acquiring accurate data of fault information for complex mechanical and electrical products is the foundation of the condition monitoring.

Moreover, the current condition monitoring stays on the traditional data analysis method. We want to set up online environment of data driven monitoring based on the internet technologies and decision support methods. This paper briefly discusses the basic principle and method of data-driven condition monitoring, preventive maintenance and quality analysis via RS and AHP. The corresponding decision algorithm was presented to the quality analysis system and the effectiveness of these methods was proved by the prediction of elevator door operation system with data-driven condition monitoring. The arrangements and measures in quality analysis system for elevators based on RS and AHP were described and discussed in this paper.

The paper is organized as follows. Section 2 describes a new approach to condition monitoring of fault information and quality analysis system by using RS and AHP method, and the implementation framework process of the approved approach is demonstrated. In Section 3, an illustrative example of a vertical elevator is presented to explain the contribution of the new approach. The hierarchic architecture model for the quality analysis system model of a vertical elevator door is established based on AHP theory. And the simplification of RS method is used in condition monitoring of fault information. Finally, this paper provides some beneficial conclusions and reference for the future work

\section{A NEW APPROACH OF CONDITION MONITORING OF FAULT INFORMATION AND QUALITY ANALYSIS SYSTEM}

Many scholars have done lots of research work on comprehensive decision methods of fault information and quality analysis. RS and AHP have been applied to complex products condition monitoring system and have demonstrated practical value on improvement to the system analysis precision. In this paper, the implementation process of the new approved approach to condition monitoring of fault information and quality analysis system for complex mechanical and electrical products is shown in Fig. 1.

A data-driven condition monitoring system is an information collection and management system which was applied for work of quality analysis technology. When monitoring condition of fault information, it is most beneficial to have our decisions to be as thoughtful and data-driven as possible. In this paper, the comprehensive decision method was used to make quality decision of the elevator quality, which is the basis of scientific decisionmaking and democratization. To increase operation efficiency and reliability of complex products, a condition monitoring and quality analysis system based on Internetbased system platform is used to products quality analysis and decision. For improving the decision efficiency, automation of condition monitoring for complex mechanical and electrical products systems, RS and AHP theory are presented in this paper. On-line measuring and monitoring and control of fault information are performed instead of subjective human manipulation. It provides effective means with ease of understanding and allows for making scientific decisions correctly. Due to the shortcomings of the single decision method, the subjective weighting method is a qualitative decision method that can be combined with experts' experience. So, the weight was determined according to the correlation and variation coefficient of each index by using the objective weighting decision method combining with actual data source. The subjective weight and objective weight are organically combined by the golden ratio in this paper, which can overcome the defects of two kinds of methods. The final decision is more reasonable after combining the complement advantages of both methods. Moreover, the elevator is an intelligent control system with complex structure that could be easy to damage and difficult to maintain. If the elevator or failure cannot start normally or shut down, it will cause the system to fail and possibly cause a serious radiological accident.

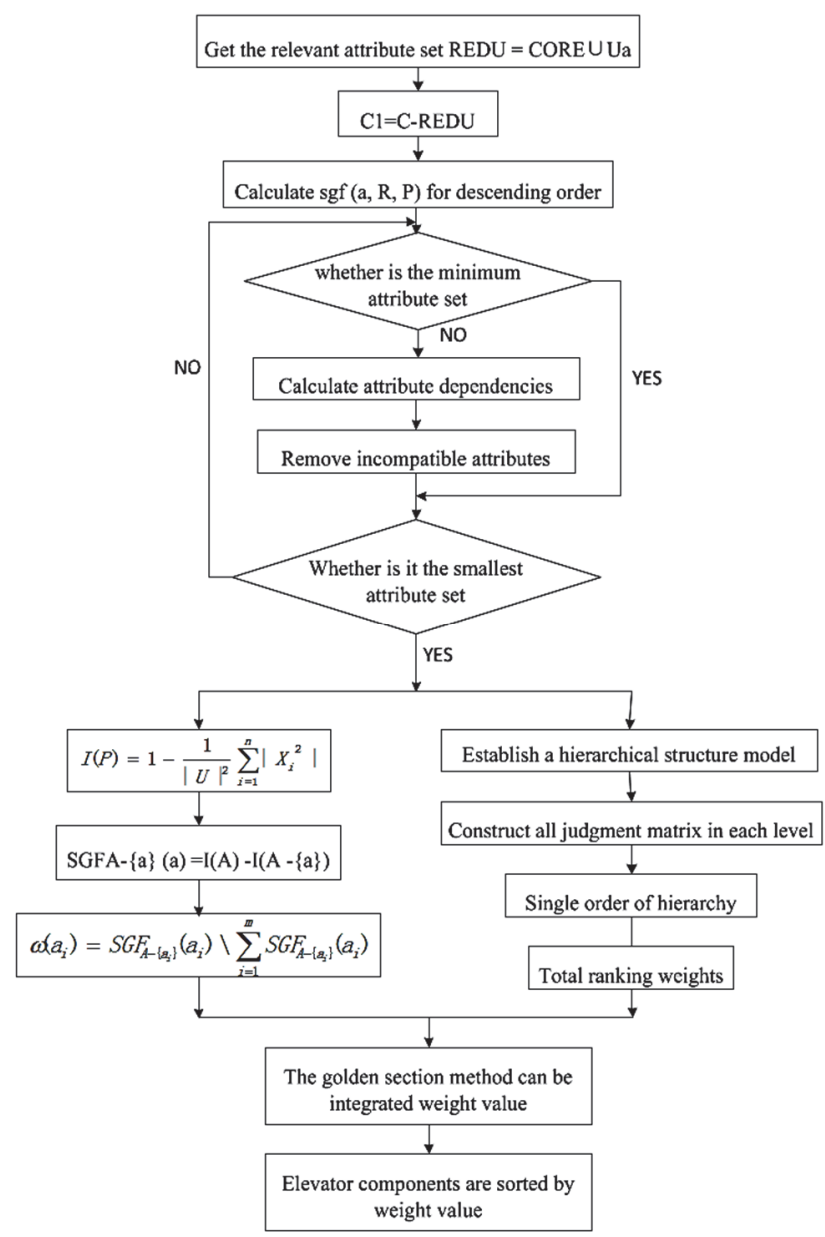

Figure 1 Implementation process of condition monitoring of fault information and quality analysis system

\subsection{Rough Set}

The rough set theory was proposed in 1982 and the continuous development of scientific researchers on RS theory has been reported since then [12]. At present, RS theory is applied to various fields such as machine learning, fault diagnosis, control algorithm acquisition, process control and knowledge acquisition in relational database, and has achieved great success. In brief, the RS theory is quite an efficient means to deal with complex system and 
a good framework for knowledge acquirement [13-15]. There are seven key steps to build a decision-centric management system in the RS method.

Step 1: Information system and knowledge reduction

Let $S=(U, A, V, f)$ is an information system, where $U$ represents a non-empty finite set of objects, $U=\left\{X_{1}, X_{2}, \ldots\right.$, $\left.X_{n}\right\}$ called a domain [16]. $A$ represents a non-empty finite set of attributes, $A=\left\{A_{1}, A_{2}, A_{m}\right\}, a_{j}(j \leq m)$ is called an attribute; $V_{a}$ is the range of the attribute $a$; Let us assume that $f: U \times A \rightarrow V$ is an information function for each attribute of each object given a value of information, namely $a \in A, x \in U, f(x, a) \in V_{a}$. In the process of classification, individuals with little difference are attributed to the same class, and their relationship is an indistinguishable relationship, which is shown in the following:

$$
\operatorname{IND}(P)=\{(x, y) \in U \times U: f(x, a)=f(y, a), a \in P\}
$$

Step 2: Approximation set

The next approximation of the set $X$ about $R$ is the largest set of objects, which must be based on the existing knowledge that belongs to $X$, and $\operatorname{POS}(X)$. The upper approximation of set $X$ is:

$$
R_{*}(X)=\{x \in u: R(x) \subseteq X\}
$$

where, $X$ with respect to $R$ is the sum of all $x$-intersecting non-null equivalent of $R(X)$, which is represented as shown below.

$$
R^{*}=\{x \in u: R(x) \cap X \neq \varnothing\}
$$

Where, $R_{*}(X)$ is the set of all objects from $U$, which can be certainly classified as elements of $X$ and the set of attributes $R$. And $R^{*}(X)$ is the set of all objects from $U$ which can be possibly classified as elements of $X$ employing the set of attributes $R$.

If we distinguish in an information system of two disjoint classes of attributes, called condition and decision attributes, then the system will be called a decision table and will be denoted by the $D T=\{U, C, U, D, V, f\}$, where $C$ and $D$ are disjoint sets of condition and decision attributes respectively. The attributes reduction method is based on the difference of dependency.

Step 3: Dependency of attributes

The decision attribute set $D$ depends on the conditional attribute set $C$, it is represented as follows.

$$
g_{\mathrm{c}}(D)=\frac{\left|P O S_{\mathrm{c}}(D)\right|}{|U|}
$$

Where $P O S_{\mathrm{c}}(D)=U_{X} \in I N D(D) C(X)$, it was called a positive region of the partition $U / I N D(D)$ with respect to $C$, which is the set of all $x \in U$ that can be uniquely classified to blocks of the partition $U / I N D(D)$ by means of $C$. If $g_{\mathrm{c}}(D)$ $=1, D$ depends on $C$ and the decision table is consistent. If $0<g_{\mathrm{c}}(D)<1, D$ depends partially on $C$ and the decision table is partially inconsistent, and if $g_{\mathrm{c}}(D)=0, D$ is totally independent on $C$ and the decision table is completely inconsistent.

Step 4: Importance of attributes

Different attributes would play a role in determining the degree of dependency between decision indicators [17, 18]. Let attribute a represent to the conditional attribute set $R$, and the importance of classification can be defined in the following:

$$
S G F(a, R, P)=g_{R}(P)-g_{R-\{\mathrm{a}\}}(P)
$$

If $S G F(a, R, D)=0$, then attribute $a$ can be removed from the set of condition attributes. In fact, the ideas of the proposed attribute significance measures originate from the positive region dependency.

Step 5: Property simplification and nuclear

In a decision-making system, there are often some dependencies and classifications in the conditional attributes. Simplification can be applied without lots of information while representing the decision attribute of the decision system [19]. And the set of condition attributes represents the information dependencies and classification.

Let us suppose a given decision system $S=\{U, A=C$ $\cup D, V, f\}$, and the simplification of conditional attribute $C$ is a nonempty subset $C^{\prime \prime}$ of $C$, then $\operatorname{IND}\left(C^{\prime},\{d\}\right)=$ $\operatorname{IND}(C,\{d\})$. If no $C^{\prime \prime}$, then $\operatorname{IND}\left(C^{\prime \prime},\{d\}\right)=\operatorname{IND}(C,\{d\})$. It satisfies that all the reduced sets of $C$ is denoted $R E D(C)$, and the intersection of all reduced sets of $C$ is called a kernel, denoted as $\operatorname{CORE}(C), \operatorname{CORE}(C)=\cap \operatorname{RED}(C)$. Therefore, simplification $B$ of $C$ can be used instead of $C$ without any data losing in the information table, and we can get to a simplified message.

Step 6: Importance measurement of information system properties.

Let $S=(U, A, V, f)$ is an information system, $U / I N D(P)$ $=\left\{X_{1}, X_{2}, \ldots, X_{n}\right\}$, which is defined as:

$I(P)=\sum_{i=1}^{n} \frac{\left|X_{i}\right|}{|U|}\left|1-\frac{\left|X_{i}\right|}{|U|}\right|=1-\frac{1}{|U|^{2}} \sum_{i=1}^{n} X_{i}^{2} \mid$

where $X$ represents the cardinal number of the set $X, X_{i} / U$ represents the relative cardinality of the equivalent class $X_{i}$ of $U$.

Then, let $S=(U, A, V, f)$ be an information system, the importance of the attribute $A$ is defined in the following:

$S G F_{A-\{a\}}(a)=I(A)-I(A-\{a\})$

The above definition shows the importance of attribute $a$ of $A$ is a change in the amount of information, which was caused by $A$ removed after $\{a\}$ size measurement. If $S G F_{A-\{a\}}(a)=0$, then attribute $a$ can be removed from the set of condition attributes. In fact, the ideas of the proposed attribute significance measures originate from the positive region dependency.

Step 7: Determination of index weight based on $R S$

In this paper, we assume that $S=(U, A, V, f)$ is an information system, $A=\left\{a_{1}, \ldots, a_{n}\right\}, a_{i} \in A$ is representative of $S G F_{A-\{a i\}}\left(a_{i}\right), a_{i} \in A$ is defined as follows. 


$$
w\left(a_{i}\right)=S G F_{A-\left\{a_{i}\right\}}\left(a_{i}\right) / \sum_{i=1}^{m} S G F_{A-\left\{a_{i}\right\}}\left(a_{i}\right)
$$

\subsection{Analytic Hierarchy Process}

The AHP is a multi-criterion decision-making tool that has been used in most applications pertaining to decision making. AHP enables to handle the above-mentioned problems in an exemplary manner. AHP theory is an assessing method which combines quantitative analysis and qualitative analysis [20]. The basic idea of AHP is to decompose the complex problem into several levels based on people's experience and judgment [21]. Moreover, AHP is usually used to determine the weight by the combination of qualitative and quantitative methods [22]. From the view of system sciences, the objective weight of different level index of the assessment model was established based on AHP method [23-25]. To deal with the problem, the following steps of AHP are shown as follows.

Step 8: Establishing hierarchy model

Firstly, the scope of the problem, involved correlation between factors, affiliation and the final answer need to be clarified. Then, the hierarchy analysis structure model should be constructed in considering different cases.

Step 9: Building judgment matrix of each level

In general, the method of pairwise comparison was used to establish a pairwise comparison matrix [26]. We can take two factors $x_{i}$ and $x_{j}$ each time, use $a_{i j}$ to represent the influence ratio of $x_{i}$ and $x_{j}$ to $Z$, use $A=\left(a_{i j}\right)_{n \times n}$ represents all the comparison results. Suppose that $A$ is $a$ pairwise comparison judgment matrix between $Z-X$ with factor contrast scales [27]. And the judgment of the importance of factor contrast scale is shown in Tab. 1.

Table 1 Judgment of the importance of factor contrast scale

\begin{tabular}{|c|l|}
\hline Scales & $\begin{array}{l}\text { Specific meaning of reciprocal judgment compared } \\
\text { with two factors }\end{array}$ \\
\hline 1 & The two factors are equally important. \\
\hline 3 & The former is slightly more important than the latter. \\
\hline 5 & $\begin{array}{l}\text { The former is obviously more important than the } \\
\text { latter. }\end{array}$ \\
\hline 7 & The former is more important than the latter. \\
\hline 9 & The former is a lot more important than the latter. \\
\hline $2,4,6,8$ & The median is given to adjacent judgments. \\
\hline Reciprocal & $\begin{array}{l}\text { If the ratio importance of factor } i \text { to the factor } j \text { is } a_{i j}, \\
\text { then the ratio of factor } j \text { to factor } i \text { is } a_{i j}=1 / a_{i j} .\end{array}$ \\
\hline
\end{tabular}

Step 10: Reliability design optimization

In this paper, we assume that the matrix $A$ corresponds to eigenvector $\boldsymbol{W}$ of the maximum eigenvalue $\lambda_{\max }$, and the normalized value is the rank value of corresponding factor of same level to relative importance. This process is called hierarchical single rank.

If the largest eigenvalue $\lambda_{\max }$ of $A$ is used to correspond the eigenvector $\boldsymbol{W}$, then we can get $\boldsymbol{W}=\left(w_{1}, w_{2}, \ldots, w_{n}\right)^{\mathrm{T}}$, and $a_{i j}=w_{i} / w_{j}$, where ,and symmetric matrix $A$ can be expressed as:

$$
A=\left[\begin{array}{ccccc}
a_{11} & a_{12} & a_{13} & \cdots & a_{1 n} \\
a_{21} & a_{22} & a_{23} & \cdots & a_{2 n} \\
a_{31} & a_{32} & a_{33} & \cdots & a_{3 n} \\
\cdots & \ldots & \cdots & \cdots & \cdots \\
a_{n 1} & a_{n 2} & a_{n 3} & \cdots & a_{n n}
\end{array}\right]=\left[\begin{array}{ccccc}
\frac{w_{1}}{w_{1}} & \frac{w_{1}}{w_{2}} & \frac{w_{1}}{w_{3}} & \ldots & \frac{w_{1}}{w_{n}} \\
\frac{w_{2}}{w_{1}} & \frac{w_{2}}{w_{2}} & \frac{w_{2}}{w_{3}} & \ldots & \frac{w_{2}}{w_{n}} \\
\frac{w_{3}}{w_{1}} & \frac{w_{3}}{w_{2}} & \frac{w_{3}}{w_{3}} & \ldots & \frac{w_{3}}{w_{n}} \\
\ldots & \ldots & \ldots & \ldots & \ldots \\
\frac{w_{n}}{w_{1}} & \frac{w_{n}}{w_{2}} & \frac{w_{n}}{w_{3}} & \ldots & \frac{w_{n}}{w_{n}}
\end{array}\right]
$$

where $\omega_{i}$ is the weight of the first element and the weight of $i$ element.

As a result, we can get the following formula.

$$
\left\{\begin{array}{l}
a_{i j}=1,(i=j) \\
a_{i j}=\frac{1}{a_{j i}},\left(a_{i j}>0\right) \\
i=1,2,3, \ldots, n ; j=1,2,3, \ldots, n .
\end{array}\right.
$$

Based on the consistent judgment matrix, each column can be used as a weight vector. Since the value of the importance of decision makers is affected by the environmental performance of an organization, the consistency of judgment matrix is difficult to be accurately established. So each column is only approximated to the weight vector. At the same time, the square root method can be used to calculate each column vector of matrix, which is geometrically averaged and normalized. Then, the obtained column vector is the weight vector of $\boldsymbol{\omega}=\left(\boldsymbol{\omega}_{1}\right.$, $\left.\omega_{2}, \ldots, \omega_{n}\right)^{\mathrm{T}}$, which is shown in the following:

$$
\begin{aligned}
\omega_{i} & =\frac{d_{i}}{\sum_{i=1}^{n} d_{i}} \\
d_{i} & =\left(\prod_{j=1}^{n} a_{i j}\right)^{\frac{1}{n}}, i=1,2, \ldots, n .
\end{aligned}
$$

In the construction process of judgment matrix, $a_{i j}$ is assigned by the decision maker, and the constructed matrix $A$ does not necessarily satisfy the consistency. When the matrix deviation is too large, the reliability of constructed judgment matrix is doubtful. Therefore, it is necessary to check the matrix consistency, the test steps are as follows.

Firstly, the maximum eigenvalue of the judgment matrix can be calculated.

$\lambda_{\max }=\frac{1}{n} \sum_{i=1}^{n} \frac{\sum_{i=1}^{n} a_{i j} \omega_{j}}{\omega_{i}}$

Secondly, the consistency indicators $C I$ can be defined as follows:

$C I=\frac{\lambda_{\max }-n}{n-1}$ 
where, $\lambda_{\max }$ is the maximum eigenvalue of the judgment matrix, $m$ is the order of the judgment matrix.

Then, the corresponding average of random consistency index $R I$ is shown in Tab. 2.

Table $2 R /$ value corresponding to different $n$ values

\begin{tabular}{|c|c|c|c|c|c|c|c|c|}
\hline$n$ & 1 & 2 & 3 & 4 & 5 & 6 & 7 & 8 \\
\hline$R I$ & 0 & 0 & 0,58 & 0,90 & 1,12 & 1,24 & 1,32 & 1,41 \\
\hline
\end{tabular}

From Tab. 2, the compliance ratio $C R$ is defined as follows

$$
C R=\frac{C I}{R I}
$$

When $C R$ reduces, the matrix consistency increases. When $C R<0,10$, it is acceptable to judge the consistency of judgment matrix, otherwise the judgment matrix should be properly modified.

\subsection{Comprehensive Weight Model Based on RS and AHP}

In this study, a comprehensive weight of decision index combines with AHP weight and subjective weight is presented by using RS theory. The comprehensive weight is obtained by the dynamic weight, so the rationality and reliability of the decision can be improved. In order to reduce the influence of subjective factors, a comprehensive model is established for quality analysis system based on RS and AHP. Thus, the two calculations can be amalgamated as follows.

Step 11: Combination weight of optimal solution

In this study, we assume that $S=(U, A, V, f)$ is an information system. Assumed that $\omega_{\mathrm{s} i}$ and $\omega_{\mathrm{o} i}$ represents subjective weight and objective weight respectively, which is shown in the following:

$\sum_{i=1}^{n} \omega_{\mathrm{s} i}=\sum_{i=1}^{n} \omega_{\mathrm{o} i}=\sum_{i=1}^{n} \omega_{i}=1$

where $0 \leq \omega_{\mathrm{s} i} \leq 1 ; 0 \leq \omega_{\mathrm{s} i} \leq 1 ; 0 \leq \omega_{\mathrm{s} i} \leq 1 ;(i=1,2, \ldots, n)$.

The optimization model was established as follows:

$$
\begin{aligned}
& \text { s.t. }=\min \left\{\sum_{i=1}^{n}\left[m\left(\left(\left(\omega_{i}-\omega_{\mathrm{s} i}\right)^{2} / 2\right)+(1-m)\left(\left(\omega_{i}-\omega_{\mathrm{o} i}\right)^{2} / 2\right)\right)\right]\right\} \\
& \omega_{i} \in \Omega=\left\{\omega_{i} \mid \sum_{i=1}^{n} \omega_{i}=1 ; 0 \leq \omega_{i} \leq 1 ;(i=1,2, \ldots, n)\right\}
\end{aligned}
$$

Where $0 \leq \mu \leq 1$.

So, the feasible region of optimization model is a unique solution, and $\omega_{i}$ can then be calculated as:

$$
\omega_{1}=\mu \omega_{\mathrm{s} i}+(1-\mu) \omega_{\mathrm{o} i}
$$

where $i=1,2, \ldots, n$.

Step 12: Decision value formula via combination weight

Based on the optimal solution of combinatorial weight, we can set up the mathematical model of object decision value. If $\omega\left(F_{j}\right)$ and $\omega\left(X_{i}\right)$ are the combined weights of each level index, once the two-level indexing of information system was determined, the decision value of each object can be calculated by the following formula.

$D_{j i}=\omega\left(F_{j}\right) \times \omega\left(X_{i}\right)$

On this basis, a mathematical model of combination weight of RS theory and AHP method is established to confirm the combination weights of product quality analysis system.

\section{A CASE STUDY}

In this study, an on-line condition monitoring system was presented to improve the efficiency and reliability of quality analysis system for a vertical elevators door system by using RS and AHP. Combined with intelligent control techniques, the approved methods can be applied to elevator door operation fault diagnosis, information prediction, real-time control, condition monitoring and quality analysis. Condition monitoring was applied to a vertical elevator door operation fault such that it would not impact running safety. The important meaning of the application of quality analysis system for elevator door operation monitoring was illuminated in this case study.

A real-time monitoring system was implemented based on the techniques of Radio Frequency Identification (RFID), internet of things, real-time database, dynamic synchronous transfer mode and decision-making methods. The condition monitoring of many elevators was used to monitor main fault diagnosis information of elevator door operation. The application of the analysing and processing of fault information is very extensive in elevator working condition monitoring. And the real-time data restoring and transmission need a higher request to data-driven science and technology. In this study, a data-driven condition monitoring of fault information and quality analysis of vertical elevators door system is shown in Fig. 2.

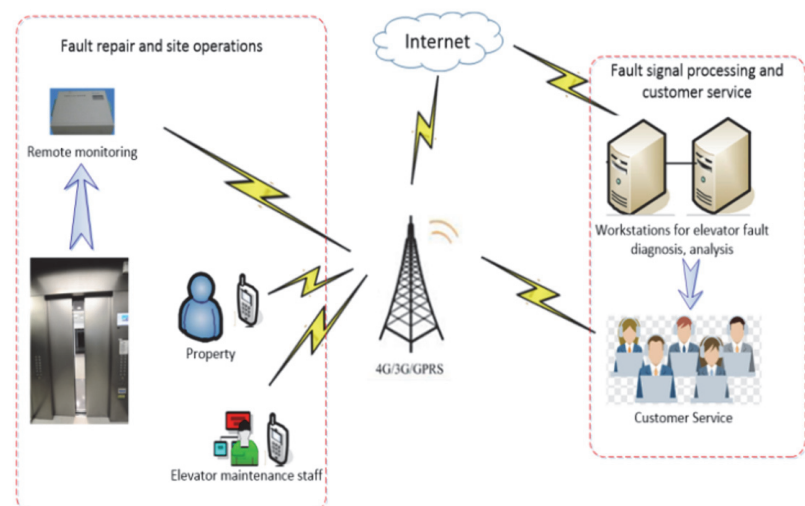

Figure 2 The data-driven condition monitoring of fault information and quality analysis of vertical elevators door

From the above diagram, the remote fault diagnosis and prediction system has a few basic functions based on the elevator running online monitoring of maintenance Local Area Network (LAN) system. The functions of the fault diagnosis and prediction system are as follows:

(1) The fault diagnosis and quality analysis can be used to carry out accurately prediction in advance and provide a 
reliable fault diagnosis conclusion to realize the predictive maintenance of elevator working status through the assessment of health status of each component in the monitoring scope.

(2) The remote real-time collection and monitoring of elevator operating status of working conditions can be received. Whenever a failure happens, the remote monitoring device can detect and send the fault code to the monitoring operation centre through the mobile network as soon as possible based on the computer analyses with the received fault code.

(3) The engineers of fault monitoring center should analyse the elevator fault information by using the feedback information on the maintenance of the elevator, and the analysis results record can be given for classification preservation and collection.

On the other hand, there are many potential causes for the failure of the vertical elevator in the daily use. According to the elevator maintenance records provided with the elevator maintenance unit, we found the highest frequency of the failure of the elevator door through the statistical analysis of the faults. Aiming at the structural characteristics and operation characteristics of vertical elevator door system, a comprehensive index model which affects the normal operation of elevator doors was established in this paper. From Fig. 2, there are four main fault modes in the elevator door operation including the following: transmission parts failure $\left(F_{1}\right)$, gate drive failure $\left(F_{2}\right)$, guide component failure $\left(F_{3}\right)$ and sensor failure $\left(F_{4}\right)$. Moreover, the operation failure mode of all kinds of elevator doors is different, which includes eleven types in the following: gate motor synchronous belt $\left(X_{1}\right)$, steering wheel plugging $\left(X_{2}\right)$, halls and door transmission wire rope $\left(X_{3}\right)$, gate motor failure $\left(X_{4}\right)$, control circuit board failure $\left(X_{5}\right)$, excessive wear of eccentric wheel $\left(X_{6}\right)$, clutter in the ground $\left(X_{7}\right)$, grease stain on door guide rail $\left(X_{8}\right)$, light screen sensor failure $\left(X_{9}\right)$, failure of gate motor speed sensor $\left(X_{10}\right)$ and gate photoelectric sensor failure $\left(X_{11}\right)$. In view of the above characteristics, the reliability factors of normal operation of elevator doors are obtained through the analysis of relevant manual and fault data. Then, a comprehensive decision hierarchy model for the quality correction of the vertical elevator door system is established in Fig. 3.

It is necessary to consider the composition, transmission principle and operation condition of elevator door to determine the quality correction coefficient. According to the different fault modes, the fault components were analysed, and the above four major fault modes were divided into quantifiable indexes, and a comprehensive index system for evaluating the difference degree was established. Taking the failure of vertical elevator door as an example, we put forward the comprehensive methods of RS and AHP. According to the maintenance record from many corporations, elevator door failure includes the following four types of faults: transmission parts failure $\left(F_{1}\right)$, gate drive failure $\left(F_{2}\right)$, guide component failure $\left(F_{3}\right)$ and sensor failure $\left(F_{4}\right)$. And the abnormal operation of elevator doors is affected by the following influencing factors: gate motor synchronous belt $\left(X_{1}\right)$, steering wheel plugging $\left(X_{2}\right)$, halls and door transmission wire rope $\left(X_{3}\right)$, gate motor failure $\left(X_{4}\right)$, control of circuit board failure $\left(X_{5}\right)$, excessive wear of eccentric wheel $\left(X_{6}\right)$, clutter in the ground $\left(X_{7}\right)$, grease stain on the guide rail of the door $\left(X_{8}\right)$, light screen sensor failure $\left(X_{9}\right)$, failure of gate motor speed sensor $\left(X_{10}\right)$ and gate photoelectric sensor failure $\left(X_{11}\right)$.

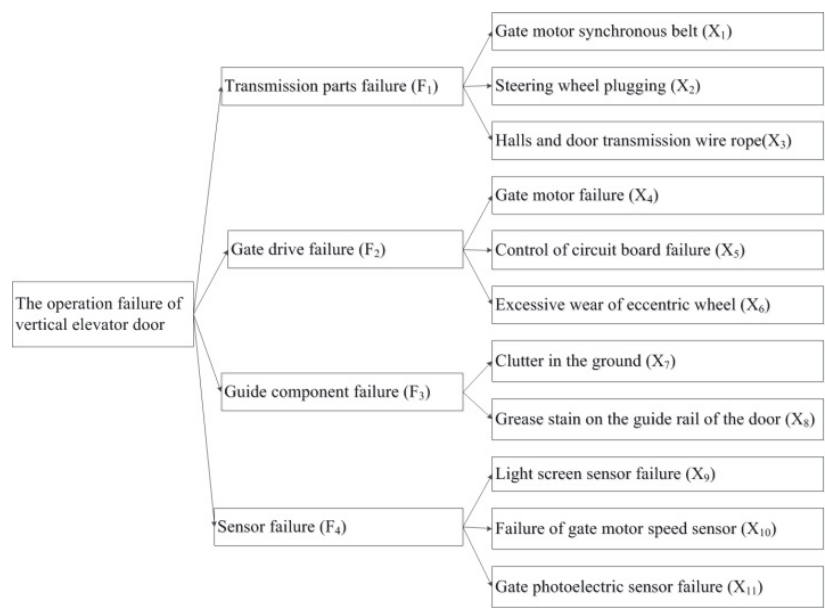

Figure 3 Quality analysis system model of vertical elevator door

The operation status of each component is then determined in the event of a door failure in the elevator. These statistical results are discretized into three states, good, normal and bad. According to 200 sets of fault statistics, the elevator door operation fault diagnosis information system is built as a discrete processing. Combination of conditional entropy and AHP, the weight of each part of elevator door failure can be calculated. During the daily maintenance of elevator, the key parts with large weight value need to be mainly maintained.

The simplification of index system was built based on RS theory. According to eight sets of fault statistics, the discrete processing was used to build the information system of fault diagnosis for elevator door operation, which is shown in Tab. 3 .

Table 3 Information system of fault diagnosis for elevator door operation

\begin{tabular}{|c|c|c|c|c|c|c|c|c|c|c|c|}
\hline $\mathrm{A}$ & $X_{1}$ & $X_{2}$ & $X_{3}$ & $X_{4}$ & $X_{5}$ & $X_{6}$ & $X_{7}$ & $X_{8}$ & $X_{9}$ & $X_{10}$ & $X_{11}$ \\
\hline $\mathrm{I}$ & 3 & 2 & 2 & 1 & 2 & 3 & 1 & 2 & 2 & 1 & 1 \\
\hline $\mathrm{II}$ & 1 & 4 & 2 & 3 & 2 & 1 & 3 & 2 & 2 & 2 & 2 \\
\hline III & 2 & 2 & 4 & 3 & 1 & 2 & 2 & 4 & 4 & 1 & 2 \\
\hline $\mathrm{IV}$ & 4 & 2 & 3 & 2 & 1 & 4 & 2 & 3 & 3 & 3 & 3 \\
\hline V & 1 & 4 & 2 & 3 & 3 & 1 & 3 & 2 & 2 & 2 & 2 \\
\hline VI & 2 & 2 & 3 & 2 & 1 & 2 & 2 & 3 & 3 & 3 & 3 \\
\hline VII & 4 & 2 & 4 & 2 & 1 & 4 & 1 & 4 & 3 & 3 & 3 \\
\hline VIII & 3 & 4 & 2 & 1 & 2 & 3 & 1 & 2 & 2 & 1 & 1 \\
\hline
\end{tabular}

All level indexes were set as the attributes, which is shown as $A=\left\{X_{1}, X_{2}, \ldots, X_{11}\right\}$. The vertical elevator door can be evaluated as a collection of objects in the system with eight types of elevator door operation fault, namely $U$ $=\{\mathrm{I}, \mathrm{II}, \ldots, \mathrm{VIII}\}$. In the decision process, the corresponding decision results of each secondary index were measured in four grades, the statistical results were discretized into four states: 1 (Excellent), 2 (Good), 3 (General) and 4 (Poor).

Then, the fault diagnosis was simplified by using the information system with $S=(U, A, V, f)$, and a simple set can be obtained as $R_{1}=\left\{X_{1}, X_{2}, X_{5}, X_{7}, X_{9}, X_{11}\right\}$. Corresponding to the information system $S$, the further reduced information system is shown in Tab. 4, and the corresponding level one and two-level index sets are $\left\{F_{1}\right.$, $\left.F_{2}, F_{3}, F_{4}\right\}=\left\{\left\{X_{1}, X_{2}\right\},\left\{X_{5}\right\},\left\{X_{7}\right\},\left\{X_{9}, X_{11}\right\}\right\}$. 
Table 4 The brief information system of rough set

\begin{tabular}{|c|c|c|c|c|c|c|}
\hline Number & $X_{1}$ & $X_{2}$ & $X_{5}$ & $X_{7}$ & $X_{9}$ & $X_{11}$ \\
\hline I & 3 & 2 & 2 & 1 & 2 & 1 \\
\hline II & 1 & 4 & 2 & 3 & 2 & 2 \\
\hline III & 2 & 2 & 1 & 2 & 4 & 2 \\
\hline IV & 4 & 2 & 1 & 2 & 3 & 3 \\
\hline V & 1 & 4 & 3 & 3 & 2 & 2 \\
\hline VI & 2 & 2 & 1 & 2 & 3 & 3 \\
\hline VII & 4 & 2 & 1 & 1 & 3 & 3 \\
\hline VIII & 3 & 4 & 2 & 1 & 2 & 1 \\
\hline
\end{tabular}

The information system $S=(U, A, V, f)$ was simplified in Tab. 4, then $U=\{\mathrm{I}, \mathrm{II}, \mathrm{III}, \mathrm{IV}, \mathrm{V}, \mathrm{VI}, \mathrm{VII}, \mathrm{VIII}\}, A=$ $\left\{X_{1}, X_{2}, X_{5}, X_{7}, X_{9}, X_{11}\right\}$.

Let $F_{1}=\left\{X_{1}, X_{2}\right\}, U / I N D\left(F_{1}\right)=\{\{I\},\{I I, V\},\{\mathrm{III}, \mathrm{VI}\}$, $\{\mathrm{IV}, \mathrm{VII}\},\{\mathrm{VIII}\}\}$, we can calculate $\mathrm{I}\left(F_{1}\right)$ through the Eq. (6):

$I\left(F_{1}\right)=1-\frac{1^{2}+2^{2}+2^{2}+2^{2}+1^{2}}{8^{2}}=\frac{50}{64}$

So we have a hypothesis that $\operatorname{UIND}\left(F_{1}-\left\{X_{1}\right\}\right)=\{\{I$, $I I I, I V, V I, V I I\},\{I I, V, V I I I\}\}$, Then:

$I\left(F_{1}-\left\{X_{1}\right\}\right)=1-\frac{5^{2}+3^{2}}{8^{2}}=\frac{30}{64}$

Through the Eq. (7), we can get:

$S G F_{F_{1}-\left\{X_{1}\right\}}\left(X_{1}\right)=I\left(F_{1}\right)-I\left(F_{1}-\left\{X_{1}\right\}\right)=\frac{50-30}{64}=\frac{20}{64}$

Thus, we can obtain good effect by using the following equation:

$S G F_{F_{1}-\left\{X_{2}\right\}}\left(X_{2}\right)=I\left(F_{1}\right)-I\left(F_{1}-\left\{X_{2}\right\}\right)=\frac{50-48}{64}=\frac{2}{64}$

By using the Eq. (8), we can get:

$\omega\left(\mathrm{X}_{1}\right)=S G F_{\mathrm{F}_{1}-\left\{\mathrm{x}_{1}\right\}}\left(X_{1}\right) / \sum_{i=1}^{2} S G F_{\mathrm{F}_{1}-\{X\}_{i}}\left(X_{i}\right)=\frac{20}{20+2} \approx 0,9091$

This is the key to computing things in practice. So we can obtain the computed weight in the following:

$$
\begin{aligned}
& \omega\left(X_{5}\right)=1,0000, \omega\left(X_{7}\right)=1,0000 \\
& \omega\left(X_{9}\right)=0,3333, \omega\left(X_{11}\right)=0,6667 \\
& \omega\left(F_{1}\right)=0,4000, \omega\left(F_{2}\right)=0,2000 \\
& \omega\left(F_{3}\right)=0,2000, \omega\left(F_{4}\right)=0,2000
\end{aligned}
$$

In the sections that follow, the decision index system of competence of the elevator door system was built by issuing the expert questionnaires. And the index weights were calculated based on AHP method. According to Tab. 1 , the importance of each index of vertical elevator door system was compared and evaluated by experts, and the relative importance of each index is obtained in Tab. 5, Tab. 6 and Tab. 7.

Table 5 Index ratio of $F_{1}$

\begin{tabular}{|c|c|c|}
\hline \multicolumn{3}{|c|}{ Table 5 Index ratio of $F_{1}$} \\
\hline$F_{1}$ & $X_{1}$ & $X_{2}$ \\
\hline$X_{1}$ & 1 & 5 \\
\hline$X_{2}$ & $1 / 5$ & 1 \\
\hline
\end{tabular}

Table 6 Index ratio of $F_{4}$

\begin{tabular}{|c|c|c|}
\hline$F_{4}$ & $X_{1}$ & $X_{2}$ \\
\hline$X_{9}$ & 1 & $1 / 7$ \\
\hline$X_{11}$ & 7 & 1 \\
\hline
\end{tabular}

\begin{tabular}{|c|c|c|c|c|}
\multicolumn{5}{c}{ Table 7 Index ratio of AHP } \\
\hline Number & $F_{1}$ & $F_{2}$ & $F_{3}$ & $F_{4}$ \\
\hline$F_{1}$ & 1 & $1 / 7$ & 9 & 5 \\
\hline$F_{2}$ & 7 & 1 & $1 / 3$ & 5 \\
\hline$F_{3}$ & $1 / 9$ & 3 & 1 & $1 / 5$ \\
\hline$F_{4}$ & $1 / 5$ & $1 / 5$ & 5 & 1 \\
\hline
\end{tabular}

According to decision indexes, the weight of each index can be calculated. The subjective and objective weight coefficient can be given by using golden number. The results of two indicators of combined weights based on RS and AHP are shown in Tab. 8 and Tab. 9.

Table 8 The index weights of the first level

\begin{tabular}{|l|c|c|c|c|}
\hline \multicolumn{1}{|c|}{ Index weight of first level } & $F_{1}$ & $F_{2}$ & $F_{3}$ & $F_{4}$ \\
\hline Analysis method of rough set & 0,4000 & 0,2000 & 0,2000 & 0,2000 \\
\hline Analysis method of AHP & 0,0760 & 0,2802 & 0,5098 & 0,1340 \\
\hline Combination method & 0,2762 & 0,2306 & 0,3183 & 0,1748 \\
\hline
\end{tabular}

Table 9 The index weight of the second level
\begin{tabular}{|l|c|c|c|c|c|c|}
\hline Level index & $X_{1}$ & $X_{2}$ & $X_{5}$ & $X_{7}$ & $X_{9}$ & $X_{11}$ \\
\hline Rough set & 0,9091 & 0,0909 & 1,0000 & 1,0000 & 0,3330 & 0,6667 \\
\hline AHP & 0,8333 & 0,1667 & 1,0000 & 1,0000 & 0,1250 & 0,8750 \\
\hline Combination & 0,8801 & 0,1199 & 1,0000 & 1,0000 & 0,2535 & 0,7463 \\
\hline
\end{tabular}

According to the weight of level indexes and the value of each object under the corresponding index, the comprehensive weights can be calculated by the Formula (20). So, the weight of comprehensive index is shown in Tab. 10. The key values of the vertical elevator door system can be evaluated as: 0,$2431 ; 0,0331 ; 0,2306 ; 0,3183$; 0,$0443 ; 0,1304$; and the comprehensive index values are from high to low is $X_{7}, X_{1}, X_{5}, X_{11}, X_{9}$ and $X_{2}$.

Based on Tab. 10, the result for the comprehensive weight index of quality analysis system is displayed in Fig. 4.

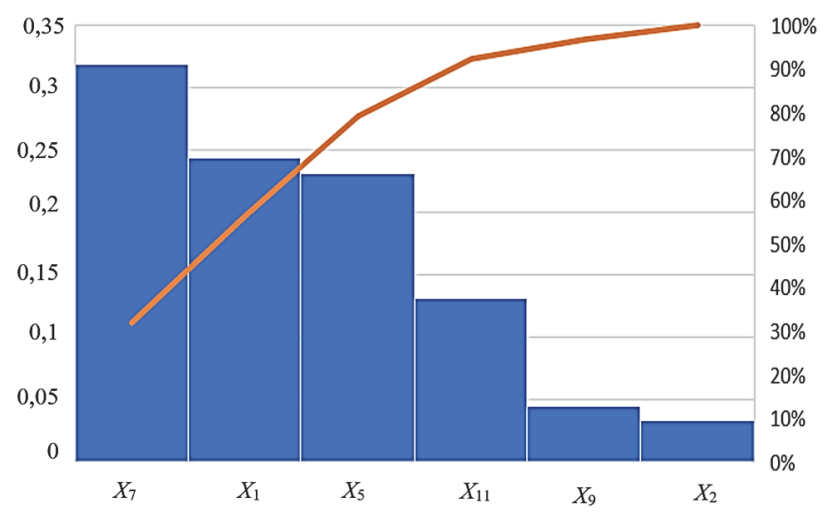

Figure 4 Weight of comprehensive index of quality analysis system

Table 10 The weight of comprehensive index

\begin{tabular}{|c|c|c|c|c|c|c|}
\hline Level index & $X_{1}$ & $X_{2}$ & $X_{5}$ & $X_{7}$ & $X_{9}$ & $X_{11}$ \\
\hline $\begin{array}{c}\text { Weight of } \\
\text { comprehensive } \\
\text { index }\end{array}$ & 0,2431 & 0,0331 & 0,2306 & 0,3183 & 0,0443 & 0,1304 \\
\hline
\end{tabular}

From above analysis, it is necessary to maintain the key parts with the comprehensive weight. In order to ensure the normal working state of the vertical elevator door system, the normal operation of the door system was 
used to reduce the failure rate of the elevator. Operation, management and maintenance personnel can quickly make informed decisions that significantly impact the performance of vertical elevator door system.

\section{DISCUSSION}

We carried out research and analysis on the most common opening and closing faults in the normal use of vertical elevator, and summarized the fault points through daily maintenance data. The main reasons for the faults included the following 11 points: gate motor synchronous belt $\left(X_{1}\right)$, steering wheel plugging $\left(X_{2}\right)$, halls and door transmission wire rope $\left(X_{3}\right)$, gate motor failure $\left(X_{4}\right)$, control of circuit board failure $\left(X_{5}\right)$, excessive wear of eccentric wheel $\left(X_{6}\right)$, clutter in the ground $\left(X_{7}\right)$, grease stain on the guide rail of the door $\left(X_{8}\right)$, light screen sensor failure $\left(X_{9}\right)$, failure of gate motor speed sensor $\left(X_{10}\right)$ and gate photoelectric sensor failure $\left(X_{11}\right)$. By using the method of RS and AHP, the different important degrees of fault point were calculated with the important degree sorting point of failure.

The RS and AHP mentioned in this paper do not need any prior information other than the obtained data, such as subjective judgment, hypothesis or membership function, etc. The results are derived from the calculation of actual survey results, ensuring the objectivity of the data. The inexact information of rough number pairs is expressed in the form of rough boundary intervals containing upper and lower limits which can be calculated directly from the collected original data.This indicates that rough numbers can find the uncertainty and ambiguity implicit in the data, and the rough boundary interval is more flexible than the fuzzy interval, which assumes that all cognitive differences are equidistant. Compared with other numerical methods, the hierarchical decomposition of AHP and the calculation of rough number and rough interval can effectively deal with the situation of multiple decision-makers and multiple demands. The evaluation of demand importance derived from rough numbers can better reflect the true perception of customers, especially the overall cognition of the investigated customer group, and the result may be more convincing and acceptable from the practical example.

Although we have ignored some factors of the experimental results, the new methods are worth extending and popularizing with the effectiveness of practical quality analysis system. By sorting the importance of the key positions that affect the normal operation of vertical elevator subway, it is beneficial to the maintenance and inspection of the key positions by elevator maintenance personnel. The application of the methods in the actual case can greatly improve the daily work efficiency and reduce the occurrence of elevator failure.

\section{CONCLUSION}

With the development of economy and society, building the condition monitoring of fault information and quality analysis system for complex mechanical and electrical products becomes more and more important. This paper analyzed the product quality monitoring system and gives some advices on guaranteeing the operation quality. To get the comprehensive decision model of quality analysis system, the model with logical reasoning and theoretical basis based on the RS and AHP was established. The characteristics of the two methods were also compared and analyzed respectively. And the quality analysis system was operated with data mining technology for monitoring and checking complex mechanical and electrical products with fault finding and correction information by using RS and AHP. The result showed that RS and AHP method is a special decision support tool for quality analysis system. Thus, this paper presented a research on condition monitoring of fault information by movement data and operational research theory and information management method. Moreover, model identification with complex decision methods is very important to the quality system stability analysis and control.

To this end, we monitor the product quality system to challenge a number of methods, aimed at establishing more effective monitoring system and improving the operation quality. The effectiveness of the approved methods and their learning algorithms were proved by the elevator faults prediction in the long-distance condition monitoring, and the computational results are satisfactory. The example shows that the decision is feasible effective and provides a new way for monitoring the product quality system of vertical elevator door. In future research, we would try to use the approved comprehensive method to solve the correspondence problem of other complex mechanical and electrical products.

\section{Acknowledgements}

This work was supported by the National Natural Science Foundation of China (No. 71671130), and the Provincial Natural Science Foundation, Zhejiang, China (No. LY20G010014).

\section{REFERENCES}

[1] Liu, S., Du, S., \& Xi, L. (2018). Transient analysis of quality performance in two-stage manufacturing systems with remote quality information feedback. Computers \& Industrial Engineering, 117, 262-281. https://doi.org/10.1016/j.cie.2018.02.009

[2] Du, S., Xu, R., Huang, D., \& Yao, X. (2015). Markov modeling and analysis of multi-stage manufacturing systems with remote quality information feedback. Computers \& Industrial Engineering, 88, 13-25. https://doi.org/10.1016/j.cie.2015.06.012

[3] Farahani, A., Tohidi, H., \& Shoja, A. (2019). An integrated optimization of quality control chart parameters and preventive maintenance using Markov chain. Advances in Production Engineering \& Management, 14(1), 5-14. https://doi.org/10.14743/apem2019.1.307

[4] Wang, J., Li, J., Arinez, J., Biller, S., \& Huang, N. (2010). Quality Analysis in Flexible Manufacturing Systems with Batch Productions: Performance Evaluation and Nonmonotonic Properties. IEEE Transactions on Automation Science and Engineering, 7(3), 671-676. https://doi.org/10.1109/TASE.2009.2029077

[5] Dragomir, E. G. (2014). Development of a Multi-AgentBased Simulation System for Air Quality Analysis. Studies in Informatics and Control, 23(4), 371-380. https://doi.org/10.24846/v23i4y201407

[6] Chang, Y. W. \& Lee, S. H. (2013). A Development of a Web-Based and User-Centered Process Analysis System for 
Quality Improvement. International Journal of Precision Engineering and Manufacturing, 14(12), 2165-2170. https://doi.org/10.1007/s12541-013-0293-6

[7] He, Y., Gu, C., Chen, Z., \& Han, X. (2017). Integrated predictive maintenance strategy for manufacturing systems by combining quality control and mission reliability analysis. International Journal of Production Research, 55(19), 58415862. https://doi.org/10.1080/00207543.2017.1346843

[8] Attri, R. \& Grover, S. (2018). Analysis of quality enabled factors in the product design stage of a production system life cycle: a relationship modelling approach. International Journal of Management Science and Engineering Management, 13(1), 65-73. https://doi.org/10.1080/17509653.2017.1298480

[9] Liukkonen, M., Havia, E., Leinonen, H., \& Hiltunen, Y. (2011). Expert system for analysis of quality in production of electronics. Expert Systems with Applications, 38(7), 8724-8729. https://doi.org/10.1016/i.eswa.2011.01.081

[10] Wuest, T., Irgens, C., \& Thoben, K.-D. (2014). An approach to monitoring quality in manufacturing using supervised machine learning on product state data. Journal of Intelligent Manufacturing, 25(5), 1167-1180. https://doi.org/10.1007/s10845-013-0761-y

[11] Kano, M. \& Nakagawa, Y. (2008). Data-based process monitoring, process control, and quality improvement: Recent developments and applications in steel industry. Computers \& Chemical Engineering, 32(1-2), 12-24. https://doi.org/10.1016/j.compchemeng.2007.07.005

[12] Pawlak, Z. \& Skowron, A. (2007). Rudiments of rough sets. Information Sciences, 177(1), 3-27. https://doi.org/10.1016/j.ins.2006.06.003

[13] Lin, G., Qian, Y., \& Li, J. (2012). NMGRS: Neighborhoodbased multigranulation rough sets. International Journal of Approximate Reasoning, 53(7), 1080-1093. https://doi.org/10.1016/j.ijar.2012.05.004

[14] Liang, J., Wang, F., Dang, C., \& Qian, Y. (2014). A Group Incremental Approach to Feature Selection Applying Rough Set Technique. IEEE Transactions on Knowledge and Data Engineering, 26(2), 294-308. https://doi.org/10.1109/TKDE.2012.146

[15] Li, H. \& Zhou, X. (2011). Risk Decision Making Based on Decision-theoretic Rough Set: A Three-way View Decision Model. International Journal of Computational Intelligence Systems, 4(1), 1-11. https://doi.org/10.1080/18756891.2011.9727759

[16] Das, A. K., Sengupta, S., \& Bhattacharyya, S. (2018). A group incremental feature selection for classification using rough set theory based genetic algorithm. Applied Soft Computing, 65, 400-411. https://doi.org/10.1016/j.asoc.2018.01.040

[17] Dai, J. \& Xu, Q. (2013). Attribute selection based on information gain ratio in fuzzy rough set theory with application to tumor classification. Applied Soft Computing, 13(1), 211-221. https://doi.org/10.1016/j.asoc.2012.07.029

[18] Chebrolu, S. \& Sanjeevi, S.G. (2017). Attribute reduction on real-valued data in rough set theory using hybrid artificial bee colony: extended FTSBPSD algorithm. Soft Computing, 21(24), 7543-7569. https://doi.org/10.1007/s00500-016-2308-6

[19] Bai, C. \& Sarkis, J. (2010). Green supplier development: analytical evaluation using rough set theory. Journal of Cleaner Production, 18(12), 1200-1210. https://doi.org/10.1016/j.jclepro.2010.01.016

[20] Vaidya, O. S. \& Kumar, S. (2006). Analytic hierarchy process: An overview of applications. European Journal of Operational Research, 169(1), 1-29. https://doi.org/10.1016/j.ejor.2004.04.028

[21] Subramanian, N. \& Ramanathan, R. (2012). A review of applications of Analytic Hierarchy Process in operations management. International Journal of Production Economics, 138(2), 215-241. https://doi.org/10.1016/j.ijpe.2012.03.036

[22] Sahoo, S., Dhar, A., \& Kar, A. (2016). Environmental vulnerability assessment using Grey Analytic Hierarchy Process based model. Environmental Impact Assessment Review, 56, 145-154. https://doi.org/10.1016/j.eiar.2015.10.002

[23] Haider, S., Ahmad, J., \& Ahmed, M. (2018). Identifying barriers to implementation of health promoting schools in Pakistan: The use of qualitative content analysis and fuzzy analytic hierarchy process. International Journal of Advanced and Applied Sciences, 5(4), 56-66. https://doi.org/10.21833/ijaas.2018.04.007

[24]Govindan, K., Kaliyan, M., Kannan, D., \& Haq, A. N. (2014). Barriers analysis for green supply chain management implementation in Indian industries using analytic hierarchy process. International Journal of Production Economics, 147, 555-568. https://doi.org/10.1016/j.jpe.2013.08.018

[25] Ghaitidak, D. M. \& Yadav, K. (2018). An investigation on greywater treatment options for reuse: ranking by analytic hierarchy process. Environmental Engineering and Management Journal, 17(3), 649-660. https://doi.org/10.30638/eemj.2018.066

[26] Ergu, D., Kou, G., Peng, Y., Shi, Y., \& Shi, Y. (2013). The analytic hierarchy process: task scheduling and resource allocation in cloud computing environment. Journal of Supercomputing, 64(3), 835-848. https://doi.org/10.1007/s11227-011-0625-1

[27] Frikha, A. \& Moalla, H. (2015). Analytic hierarchy process for multi-sensor data fusion based on belief function theory. European Journal of Operational Research, 241(1), 133-147. https://doi.org/10.1016/j.ejor.2014.08.024

\section{Contact information}

\section{Jihong PANG}

College of Mechanical and Electrical Engineering,

Wenzhou University, Wenzhou 325035, P. R. China

\section{Ruiting WANG,}

College of Mechanical and Electrical Engineering,

Wenzhou University, Wenzhou 325035, P. R. China

Quan XIAO,

School of Information Management

Jiangxi University of Finance and Economics,

Nanchang 330032, P.R. China

Feifei QIN,

(Corresponding author)

School of Information Science and Engineering

Wenzhou Business College, Wenzhou 325035, P. R. China

helloqinfeifei8@sohu.com 